\title{
Kidney Angiosarcoma
}

National Cancer Institute

\section{Source}

National Cancer Institute. Kidney Angiosarcoma. NCI Thesaurus. Code C159205.

A rare angiosarcoma arising from the kidney. 